\title{
On letting go
}

\section{John Foster}

Lancaster University,

Lancaster, UK.

j.foster@lancaster.ac.uk

\begin{abstract}
:
Massively disruptive climate change, now inevitable, is the worst tragedy which human beings have yet brought on themselves. It is tragic in the full classical sense - a disaster entailed on the protagonist (here, humanity) by destructive weaknesses inherent in crucial strengths and virtues. There is thus no way of avoiding it by picking and choosing among our values, and its effects can neither be compensated for nor mitigated by prospective gains to offset against anticipated losses. But once we have discarded a strained and wilful last-ditch optimism, and recognised that we are not in control, we will still need to find genuine hope if we are to have any chance of coming through. This requires us to embrace the transformative power of tragic experience, letting go of values which we may hitherto have regarded as sacrosanct and welcoming the creative destruction of current assumptions and expectations as an affirmation of life.
\end{abstract}

Keywords: climate change, Enlightenment, hope, optimism, sustainability, tragedy, values.

"Therefore the sage manages affairs without action

Ten thousand things arise and he does not initiate them, They come to be and he claims no possession of them, He works without holding on ....."

\section{Tao Te Ching ${ }^{1}$}

\section{I.}

How do we approach the worst tragedy which human beings have ever brought on themselves, in the recognition that its coming to pass is now inevitable? How might we advance with eyes open into this ending of the world as we have known it, without taking it for the end of the world - letting go of what we must, without losing the hope which is essential to living? How can we give up pretending without giving up altogether?

The tragedy, of course, is anthropogenic climate change ${ }^{2}$. I assume here an audience which accepts without reservation, what the overwhelming majority of relevant scientific expertise

\footnotetext{
${ }^{1}$ Ch2, v3; from Chen (1989).
} 
has for a good while fully endorsed (see e.g. Oreskes, 2004), that the global climate is being irreversibly altered and that human activity is responsible. But the further claims, that this entails a short-to-medium-term future both uniquely grievous and now inescapable, may well need defending even to people who accept the reality of the underlying process.

Inescapability is the simpler claim to demonstrate. The best way to enforce it is by appealing to what I have elsewhere called the Vicious Syllogism: if we had been going to avert the massively disruptive climate change and associated ecological degradation which will shortly start turning present global civilisation upside down, we'd have begun to put effective policies in place forty years ago when these concerns were first seriously mooted; we didn't; so we won't avoid it. This argument is valid and its premises are plainly true; in particular, the hypothetical major premise asserting that we are out of time is as well-grounded in the scientific evidence and in economic, sociological and geopolitical realism as any empiricallybased counterfactual could hope to be. The prospect of our acting collectively to turn the lumbering super-tanker of the carbon-dependent global economy around on a sixpence in the few years we have left before levels of atmospheric carbon dioxide take us past the tipping point (if they haven't already) is simply incredible, on all those counts, to anyone seriously considering it. The conclusion of the syllogism follows by simple logic (the science of not being able to have things both ways at once) - which is not to say that refusal to accept it, indeed vehement denial of it, doesn't still prevail at all levels.

The deep roots of that denial are a separate issue - one which I tried to address in my recent book After Sustainability (Foster, 2015), which starts from the above argument. These roots go down far beneath ordinary and understandable reluctance to face up to a frightening prospect. But such reluctance clearly plays a part, and is by itself well justified. Underlying it is the tacit recognition that what now confronts us is not a problem, nor even the hyperintensification of a clutch of problems - a so-called 'wicked problem' (see Hulme 2009, 334-40) - but a genuine tragedy. And while problems, even very challenging ones, can sometimes have solutions, genuine tragedy involves terrible loss, disastrous and uncompensated, for which nothing answering to the idea of a solution makes sense. This, for a modern mind accustomed to take material and social 'progress' as its unquestioned criterion

\footnotetext{
${ }^{2}$ And not, I can now add, the Trump presidency - though this will certainly bring climate tragedy on us more swiftly and decisively, and also exemplifies in its own way the tragic crisis of Enlightenment values which I discuss below.
} 
for human affairs and the problem-solution mode as its default practical expectation, is simply not to be contemplated.

Nevertheless, and reluctance to recognise the facts notwithstanding: even if the worst-case scenario of runaway warming up to $6^{\circ} \mathrm{C}$ and beyond (Lynas 2007) is somehow avoided, the increasing climate instability to which we have already committed ourselves means that we face by around 2030, what a former UK government Chief Scientific Adviser (Beddington 2009) has described as a 'perfect storm' of food, water and energy shortages, entailing worldwide famine, disease and homelessness on an epic scale. This situation will certainly trigger enormous migrations and attempts at migration, and those currently temperate parts of the world where the immediate climatic effects of warming are likely to be comparatively less drastic will come under enormous pressure to admit refugees in numbers which would quickly overwhelm their resources and infrastructure, unless they take (as they mostly will) the hard decision to close their borders. This in turn will produce both inter-communal and international conflict, much of it inevitably armed. Gwynne Dyer's book Climate Wars (Dyer 2008) presents realistic possibilities here, under any of which it is clear that the world is set to become both a much less habitable and a much more divided, hostile and violent place.

\section{II.}

The genuinely tragic nature of this prospect shouldn't be much harder to appreciate. Tragedy is not just, in the crude journalistic solecism, any sufficiently drastic event involving death and mayhem. In the proper sense of the word, it arises when disaster ensues from and expresses destructive weaknesses which are inherent in the key life-strengths of an agent whether that agent be an individual, an institution or, as in the present case, a mode of civilisation. This pattern is very apparent in the case of climate change. Deep-seated features of the secular and instrumentally-rational Enlightenment spirit which has produced so much worthwhile life-improvement across the world have also generated a pervasive inability to rein in the relevant activities before they do irreversible damage. What slogan-makers like to call 'the success of science' is visibly collapsing under the strain of its own contradictions. The trajectory launched by Baconian ambitions for technological mastery of nature is reaching the end it was always likely to reach, since humans remain part of nature whether or not they allow themselves to forget the fact, and setting themselves over against it in a spirit of attempted mastery has inevitably turned them dangerously destructive, both of their habitat and of their inner attunement to it. The biosphere has only been able to absorb so much of the 
consequences without damage, and the limits here have now been reached - indeed, if we are persuaded by the Vicious Syllogism, they have been decisively transgressed. Distinctive human strengths which Western civilisation in particular has realised - the strengths to develop a sophisticated self-conception, to make rational deliberated choices, to base belief on evidence and empirical testing, to free ourselves from ignorance, superstition and dogma are thus existentially rooted in aspirations to mastery and control which are responsible for this decisive eco-systemic damage. The epochal material successes hitherto consequent on our strengths have worked to blind us to what we are doing in exercising them, and indeed to neutralise most strivings towards self-recognition. All the classic ingredients of tragedy are here.

Correspondingly, if we are to identify those whose fault this oncoming disaster is, they can only be ourselves, the world-wide human community, or at any rate its leading protagonists, the peoples of the West and North whom the rest strive increasingly to emulate. Attempting to blame everything on the institutional power and self-interest of corporations, for instance, while an understandable reaction in the face of much contemporary corporate behaviour, is essentially an exercise in scapegoating. Corporations exercise vast irresponsible power, create damaging pseudo-needs (especially in children) through advertising, and cause widespread ecological havoc in pursuit of their shareholders' short-term financial interests. But they could not do these things, indeed they would not exist in their current forms, had not aspiring billions across the globe (taking their cue from, but no longer confined to, the West) remained eager to buy their products and benefit materially from their innovations.

It is the equally classic purity of this pattern, as well as the extent and nature of the damage, which justifies the claim that climate change will constitute the worst tragedy which humankind has ever inflicted on itself. There have been many grievous episodes in history, some latterly producing chaos and suffering world-wide, though none, not even World War, has hitherto been systemically destructive enough to jeopardise the stability and integrity of large tracts of the biosphere on which human and all other life depends. But in every such episode to date, a driving role has been played by the traditional human vices of pride, greed and hatred, as appealed to by evil men (and women) in positions of power. This new disaster, however, we have brought upon ourselves by the headlong indulgence of what are in themselves perfectly creditable passions and desires - for equality, for recognition and respect, for general material betterment (that is, for the elimination of squalor, hunger and 
disease, as well as for lives smoothed and facilitated by 'consumer goods'). In the past these progressivist goals have elicited much that was best in our collective activity. We have latterly (since the Industrial Revolution) tried to pursue them by trading on our unprecedented new powers to tap a massive store of fossilised energy in their service, and it is our having done this in careless ignorance - and more recently, in denial-driven disregard - of the associated ecological and climatic consequences, which has betrayed us.

At this point some will ask: given that analysis, where is the tragic inevitability? Can we not retain the motives and aspirations, while redeploying our powers in ways which henceforth do respect the biospheric constraints under which we must work? - so that even if it is too late for avoidance, we may still hope to mitigate the damage done by neglect to date, and at least to minimise adverse impacts on future people.

This is of course the 'sustainability' model - and here it is necessary to recognise oncoming environmental and climate tragedy as in large measure a tragedy of sustainability, into which the related tragedies of progress, growth and (insofar as it differs) sustainable development are all now folded. This concept was meant to offer a paradigm for the way in which Enlightenment values could save us from their own consequences. It represented a progressivist solution to the problems of progressivism. Extending a universalist concern for human welfare rationally into the future, we were supposed to use our scientific knowledge to set 'planetary boundaries' (Rockstrom et al. 2009) guiding and limiting our pursuit of universal human welfare in the present. The twofold problem with this is (one might have thought) sufficiently glaring. In the first place, massively complex feedbacks and systemic sensitivities render human impacts on the biosphere into the medium-term future effectively indeterminable, so that the 'constraints' under which we are to operate have to be set by socially- and politically-driven choices rather than by the allegedly impersonal voice of science. And secondly, those choices can only be made by $u s$, that is by present people (worldwide) whose pursuit of their own material welfare is thus supposedly to be constrained. ${ }^{3}$ This puts inter-generational humanity in essentially the situation of the wellintentioned alcoholic tasked with setting his own safe drinking levels (and really trying) something which might seem to make for comedy, were the case not so evidently tragic. The sincerely universalist and scientifically-rational pursuit of real and urgent human good for the

\footnotetext{
${ }^{3}$ I have discussed this problem in detail in Foster (2008).
} 
future undermines itself and defeats its own ends through just this pursuit of the same benefits for people presently alive.

It is crucial to underline again the genuinely tragic structure of what we face. Neither embedded gross vices nor malevolent intentions but its own collective well-meaning (while at the same time self-serving) activity, is now bringing humankind to grief. This tragic structure is typically obscured, for instance, in the recently-burgeoning psychology literature which offers to analyse 'values' in relation to human environmental behaviour. This literature tends to classify groups of values in broadly opposed types, the favoured arrangement involving a four-quadrant diagram - Schwartz, for instance, a seminal voice here, sets self-transcendence against self-enhancement values, and those representing openness to change against those representing conservatism. By values he means, plausibly enough, broad conceptions of what is important in life, which serve as guiding principles in the life of a person or other social entity (Schwartz 1994). Universalism and benevolence are what he calls self-transcendence values, while achievement, power and hedonism are self-enhancement values. Characteristic sub-values falling under these various heads are then identified as:

Universalism: equality, social justice, 'world at peace'

Benevolence: helpfulness, responsibility, forgiveness

Achievement: success, ambition, capability

Power: authority, wealth, recognition

Hedonism: pleasure, enjoyment of life

Schwartz claims that such sub-values are activated in packages, so that if one's behaviour is driven principally by self-transcendence values one will be correspondingly less moved by those in the opposite quadrant (self-enhancement) and vice-versa. Thus someone concerned for equality and social justice is likely also to be concerned for helpfulness and responsibility towards others, and less likely to be motivated by wealth, recognition or the delights of consumerism.

There is certainly some cross-cultural empirical evidence for this clustering of values, and specifically in relation to environmental issues, with universalism values such as empathy for distant others and global equity being associated with ecologically-responsible and proenvironmental behaviour, whereas self-enhancement values like consumerism and competitiveness are associated with a lack of concern for the natural world, a disposition to doubt the reality of global warming and so on (see e.g. Schultz et al. 2005; also Andrews 
2017 in this Special Issue). And if this rather Manichean picture of bi-polarity were the whole story, it would be easy enough to blame our present environmental plight on the dominance of self-enhancement values (those of consumerist materialism, fostered and embedded no doubt by neo-liberal capitalism) over those self-transcendence values which might have led us to recognise and respect biospheric limits.

But whatever the evidence from statistical surveys, which familiarly have their own problems of methodology and interpretation, bi-polarity is a potentially misleading guide where progressivism is concerned. If one considers the value-nexus involved, the above categorisations decisively break down. Values driving progressivism come from every segment of Schwartz's classification. It is about universalising, on terms of equality and social justice, the social power, family security, health, capability, autonomy and freedom of human beings, presupposing peace and (at least implicitly) environmental protection (the sustainability agenda has been about making this last requirement explicit). We have been able to put together an anthropocentrically-conceived combination of values from all these quarters, thanks to the availability of technologies for releasing and utilising fossil energy. This has certainly skewed our thinking away from wisdom and unity with nature, undermining effective environmental protection and diminishing our sense of responsibility so that it applies only to human betterment. The tragedy of progressivist value might then be identified as a tragedy of anthropocentric benevolence, given by technocratic means a false sense of impunity in respect of environmental constraints. But it is a tragedy in the full sense, rather than simply a black-and-white victory (temporary or permanent) of the environmentally damaging over the environmentally benign side of our nature, precisely because the damage which we are bringing on ourselves comes out of our full evaluative complexity as human beings. Tragedy is never black-and-white - values expressing all aspects of our nature are always involved, just as they have been here.

The unfolding of this disaster has thus displayed a Sophoclean remorselessness. What deters people from looking it in the face is as much what it implies for our self-understanding and our value-commitments as for our material future. The values which it begins to look as if we shall have to give up, because not only have they been driving the damage but no imaginable state of human survival looks compatible with continuing to live by them, are the central Enlightenment values by which decent people have long defined themselves: the assertion of universal human rights to life, to equality of respect and political liberty and to the open- 
ended pursuit of material betterment. We can already, in fact, see breakdown of this valueconsensus happening on a smaller scale in relation to the current Mediterranean refugee crisis. Escapees from intolerable conditions evidently have a basic right to pursue the good life elsewhere, and those in (still) comparatively comfortable Europe therefore an obligation to accommodate and help them. But equally, Europeans have a basic right to their established folk-ways, the inherited and deeply internalised structures of feeling and community which form an essential part of their own flourishing, and on which large influxes of culturallydifferent strangers are bound to inflict disruptive change. Oncoming climate chaos will write this kind of disabling conflict within our ruling value-schema very much larger, for all those currently temperate regions of the planet which will remain broadly habitable as global temperatures increase. It is because it threatens to prevent us from continuing to build our collective activity on the full range of these compelling evaluative attachments to which we have become so accustomed, but rather will set some of them more or less violently against others, that nothing as radically tragic as this has, indeed, ever happened to us before.

\section{III.}

To repeat, then: how do we approach a tragedy of this order and these dimensions?

I mean this in the first place not as the question: what plans and dispositions do we make in order to bring whatever we can of human civilisation through it (though very clearly that question must also be asked) - but rather: how do we think about it, in the present, as a nowinevitable prospect? ${ }^{4}$ This matters because our thinking must grapple with how we might now make room for hope, the absolutely necessary basis for any practical planning and preparing at all, without misconceiving such hope in a kind of last-ditch effort of denial and avoidance.

One thing which would clearly qualify as avoidance is the belief that if we can only bring ourselves to recognise that this is going to happen, that might spur us finally to exertions sufficient to prevent its happening... That is just magic thinking. Less obviously muddled, but closely allied, is the belief that even if significant adverse climate change is now inevitable, we can at well past the eleventh hour divert its worst effects by scientific wizardry, so that somehow it won't be so bad. That would just be to pursue a 'solution' in the technocratic topdown mode of would-be planetary mangaement which has itself brought us to this pass. Both

\footnotetext{
${ }^{4}$ By we I mean, for the present: those capable of such thinking.
} 
those reactions, in fact, would now only be exercises in willed optimism, not so much a basis for necessary forethought as a deliberate refusal to see our real situation for what it is. By contrast, the hope in pursuit of which we must now task our thinking can only be what we might call tough hope: something so difficult to achieve precisely because of its utter inconsistency with letting us off the hook which we have so vigorously prepared for ourselves.

That was the kind of hope to which I meant to refer in the subtitle of my book mentioned above. I wrote about it there in terms of the opportunity potentially afforded by prospective breakdown to repossess ways of understanding ourselves which current life-modes occlude from us, as means to developing the best forms of practical resilience that we can. But the approach required for its exposition at least a sketch of plausibly retrievable practical resilience on the ground, and the danger (perhaps not avoided in that book) is that aspiring to plausibility in any such sketch risks turning retrieval, however detached from the illusions of progress, into an offer to palliate the tragic, to offer some kind of compensation for it. Progress may be over, the thought then runs, but we can at least move to more satisfactorily human-scale communities, enabling fuller and more naturally-responsible individual lives, in the process of building the resilience needed to cope with what is coming. At the very least, we shall develop stronger muscles and a more active community spirit when the smooth facility of mechanical civilisation starts to fail...

But this, I have since come to recognise, won't do either. It is an attempt to offset losses against gains, and profit-and-loss accounting of any kind is a conceptually as well as an emotionally inadequate response to tragedy. If we come to rest there, we have surely avoided or betrayed the tragic experience, shirking the reality of radical loss and damage which now actually confronts us. And such shirking, equally surely, offers no real hope for coming through.

We have rather to ask the much harder question: how can we see the tragedy itself, neither minimised nor shirked, and irrespective of whatever may ensue, as hopeful?

Here, we move onto terrain classically marked out by Friedrich Nietzsche. In The Birth of Tragedy he writes of "the metaphysical solace which... we derive from every true tragedy, the solace that in the ground of all things, and despite all changing appearances, life is 
indestructibly mighty and pleasurable..."(Nietzsche 1872: 39). And it is clear from the wider context that solace isn't meant to be even consolation, still less compensation: it is meant for a kind of exultation, both intellectual ('metaphysical') and more than intellectual, something which Yeats later called "tragic joy", that is implicit in our acknowledgement of the very forces which make the pain and destruction what they are.

But we cannot just take over Nietzsche's ideas unmodified in the present case. While we should, I believe, try to retain his perspective, which has the huge merit of taking tragedy with proper philosophical seriousness, there are two major difficulties with applying it to the tragedy of anthropogenic climate change.

The first is that Nietzsche is writing about (classical Greek) tragedy as drama, an art-form in relation to which our position is that of spectators, not protagonists. It requires a considerable effort of realignment to transfer this framework of understanding to tragedy which is going to happen to us, for real and not as symbolic representation. With tragedy on the stage, we contemplate a painful action involving the destruction of much that is admirable and good, and culminating very typically in the powerfully symbolic death of the person or persons at the centre of this action. From this we go away chastened but nevertheless with a sense of spirit somehow clarified, and a kind of enhanced vitality. But to experience this, we have to be able to walk away, back into our own continuing lives. In the tragedy now confronting us we do not have that option, and the climactic death looks destined for us, if not in every case as individuals, then as a civilisation and a way of life. The only way to take anything positive from that will be to take it through to the other side of it, and that requires us to imagine a further side that is plausibly habitable. We are thus apparently caught in a paradox of anticipation: if climate disaster is going to be terminal, its tragedy cannot yield us anything positive to take beyond it, since there will be no beyond - but to the extent that we don't see it as somehow terminal, its tragic significance will tend to be defused.

It is no surprise, accordingly, that in their interesting recent book Climate Change as Social Drama, sociologists Philip Smith and Nicolas Howe reject the classical Greek form of tragedy as an interpretive model for social action because, they claim, it "keys to fatalism". Since in these ancient dramas whatever the protagonist attempts is liable to be undone by the

\footnotetext{
5 "Hector is dead and there's a light in Troy;

We that look on but laugh in tragic joy." ('The Gyres' in Yeats, W.B. 1967: 337)
} 
intervening gods or the power of destiny, seeing our current situation in that light "does not encourage sacrifice for a cause and collective action but rather the kind of apathy that in the context of climate change leads to conventional carbon-hungry lifestyles" (2015:38). This is a rather overdrawn picture of human abjectness even for Aeschylean tragedy, since after all the gods can only work on men and women through their natural aspirations and motivations. It does, however, flag up a constant worry for anyone advancing the kind of argument which I am making here. If one cannot find a convincing account of giving up pretending without giving up altogether, then exhorting people to recognise climate chaos as now tragically inevitable does indeed run a real risk of encouraging them to disengage from any kind of remedial action and cultivate their own technology-intensive gardens while there is still time.

Smith and Howe's enterprise is to deploy literary categories going back to Aristotle's Poetics - from heroic quest, through narrative to low comedy - for help in interpreting patterns of perception and action, or inaction, on climate change. Seeking to circumvent the dangers of fatalism and apathy, they prefer to invoke tragedy on the Renaissance model of the tragedy of character. The prospect of climate chaos is then to be approached as "a hypothetical future outcome that can only arise if bad choices are made by complex sovereign decision-making agents...ranging from world leaders to ordinary citizens" (op.cit.:40). This, however, takes us straight back to climate change as no more than a very challenging or 'wicked' problem, to be solved by ensuring (surprise!) that we make good choices rather than bad. In effect it reduces to the shroud-waving use of 'tragic' which talks up the inevitability of climate disaster in order to spur us into avoiding it. As we have already seen, that line of thought is an evasion. But then, recognising it as such, we are still left with the need to find positives to take from a tragedy in which we ourselves are protagonists some of whom might conceivably come through.

The second major difficulty with invoking Nietzsche for help in confronting this prospect is represented by the kind of positive which he himself offers. His appeal is always to the 'Dionysian' life-energy which tragedy releases from the grip of Apollonian intellect (which must grasp the workings-out of Fate or circumstance in terms of their impacting on representative human character). We watch the tragic hero being inevitably defeated by the personified and stylised forces of nature, and in the very same process are forcefully reminded that, as Schopenhauer had put it, we ourselves are nature (1819: 281-2). But such an invocation of the indestructible might of life takes on a peculiarly ironic note in a context 
where what is distinctive about the tragedy now in train is that it involves, precisely, the large-scale destruction of life, and not just of the non-human life beyond the human but of the underlying biospheric substrate which all life shares. Our being opened through tragedy to an influx of natural energy from this fundamental life-source was what for Nietzsche could put us back in touch with a power "ineradicably behind and beyond civilisation" (1819: ibid.), but the essence of our present tragedy is that, given the utterly unprecedented extent and colonising force of humanised life-space right across the biosphere, there is now in effect nothing "beyond civilisation". There remain, of course, even in the long-urbanised and overpopulated British Isles, areas of wilderness and quasi-wilderness; but they subsist, while they still do, by permission or protection, and nothing genuinely wild does that. The result is that when, like safari tourists in a game reserve, we turn to the 'wild' for escape and renewal, we find only what lives within boundaries (however locally distant) which humans have set.

As I have suggested, we should hold onto a Nietzschean approach if we can - that is, the boldness to look into tragedy, rather than in various ways away from it or past it, for the possibility of hope. But what that means is that the "metaphysical solace" of which he speaks must now be sought in the conditions of human action itself, rather than in any redemptive access of life-energy from the non-human. In our world now, only the necessary preconditions of human action lie "beyond the reach of civilisation". The only non-human domain that we haven't by now decisively humanised, because we can't ever 'humanise' it, lies in the conceptual grounds of all human activity. The only way we can reconnect with the wild, with life-energy form beyond humanity which might renew both hope and joy, is to embark as courageously as we can in a radical shake-up of what we can't choose, because it forms the conceptual framework for all our choices.

It will probably take the rest of the paper to make this claim intelligible (and the paper itself is only an exploratory first attempt on its subject-matter), but some initial clarification is obviously in order. By the grounds or necessary preconditions of human activity, I mean what is conceptually basic to that activity as such - what has to be there for it to be 'activity'. That means personhood - because without a person as the origin of action, there is no real activity, merely the causal involvement of a biological entity in species-appropriate initiations and reactions. Linked to personhood must be value, the fundamental form of motivation appertaining to persons as such (as opposed to instinct, appetite and aversion, all of which we share with other forms of animal life). Correspondingly, the third conceptually necessary 
element is deliberate goal-directed engagement, because our values call for realisation through our intentionally making some things happen in the real world rather than other things.

Now these fundamentals are, it would seem, conceptually inseparable - but within that nexus of implication perhaps they are capable of bearing more than one relation to one another. Standardly, we think of the capacity to identify goals in the light of our values, and to assess the outcomes of our actions towards these goals according to how far they have succeeded in implementing those values, as a centrally defining feature of the kind of personhood conscious, agential, reflectively rational - which we take ourselves to have. This is 'Enlightenment man' in control of his own destiny - or at least, with the potential to be so, if he rises to Kant's demand that he 'dare to know'. But maybe neither value nor personhood need have these mutual bearings and implications, and maybe they can be differently understood in relation to our involvement in goal-directed action. In that case, maybe the lifeenergy sprung by environmental and climate tragedy is to be found precisely in the liberation from one pattern of self-understanding here, into a vitally different one - a new sense of the human self in evaluative action with which climate tragedy challenges us.

\section{IV.}

Tragedy, at its most basic, puts our world of value in jeopardy. It represents an anticipated triumph of what we take to be thoroughly and grievously bad over what we hold to be good, and it does so through the subversion from within, as it were, of qualities like courage or kingly authority or (in the environmental case) universalist commitment to the general welfare, which had seemed to us good and desirable. It makes sense, therefore, to start trying to get a grip on the issues which climate tragedy raises for our deep conception of human agency, by thinking about those which it raises for our stance as valuers.

Anticipating tragedy means seeing this prospective assault on our cherished values within the fully tragic framing outlined above - with disaster precipitated, that is, by destructive weaknesses recognised as inseparable from key strengths. This requires, in the first place, that what is coming cannot be understood simply as unmitigated disaster - sheer loss, mere catastrophe, felt only as pain and grief - because to experience it as such would be only to reaffirm, by the via negativa as it were, the values according to which it presents itself as disaster. Thus, to think that climate change will be irredeemably catastrophic because it will 
mean the halting and reversal of 'progress', is to anticipate it exclusively through continued, regretful but unchallenged attachment to the range of Enlightenment values, already noted, which inform that ideal. There is a very clear sense in which such an essentially defensive reaction doesn't do prospective tragedy anything like justice. Insofar as we are anticipating disaster as the upshot of weakness inherent in key strengths, that is, we must have at least begun to stand back from, to adopt a more ironic, detached and critical view of, the assumptions according to which what is coming would have to be seen as disaster unmitigated, the grievous defeat (by merely adverse circumstances) of a wholly commendable human enterprise.

But, very importantly that doesn't mean that we must instead think of climate chaos as potentially mitigated disaster - with prospective gains to be offset against the losses. That kind of accounting, as I noted above, is also radically un-tragic, and now we can see more clearly why: it is, again, a way of trying to preserve essentially untouched by prospective tragedy certain relevant values which we hold prior to undergoing it. We may indeed come to see technological-progressivism as self-defeating, and so get beyond mere regret for the values driving it, but there is a danger that, if we then expect to recover things like greater physical robustness, the spirit of community solidarity and so on (all, obviously, good things in themselves), we do no more than turn back to existing values hitherto overshadowed by those in the 'progressive' package (until that was recognised as having breakdown built into it). Thinking in such terms does indeed mean that we leave room for learning something from tragedy, as merely regretting it does not; but to have done only this would be to have remained at a level which again we must recognise to be inadequate to the experience. Tragedy taken seriously must be expected to do much more than shift the balance of emphasis among our existing values, or free us from commitments to which we were mistakenly attached so that others can come unchallenged to the fore.

That is why, despite its force and clarity, Rupert Read's paper elsewhere in this Special Issue (Read 2017) points us in a crucially wrong direction. Read wants to argue that an escalating series of climate disasters will yet carry with them as an unexpected boon an opportunity for the development of community. He hopes that the attendant breakdown of social relations founded on liberal-individualist values will be the necessarily traumatic spur to the emergence of alternatives founded in solidarity and co-operation. What this ignores is precisely that the climate disasters will cumulatively constitute climate tragedy - the 
revealed-to-be-inevitable self-undermining of the avowedly good, the genuinely admirable and strong. And tragedy, unlike mere disaster, is only itself if it strikes at our valueassumptions so deeply as to shake the whole structure.

This point is absolutely central to my argument. Tragedy shakes all our values, and not merely those which recognisably bring disastrous outcomes upon us, because it shakes our reliance on value - that is, our trust that we can make generally good choices by investing in an evaluative world-view. It tests to destruction our security in being able to make dependable moral sense of the world. Tragedy, as an art-form, is such a vital part of the human heritage of self-knowledge precisely because moral sense-making tends so readily to become routinized, habitual (we "have our principles", we "know what's right"), and our moral reflexes to lose their living responsiveness. Tragedy shows us how values as explicit commitments in moral sense-making (rules, principles, codified virtues) so frequently aren't strong, subtle or complex enough for the charges of life-energy, the stresses of deep need and self-realising impulse, which have to pass through them. Honourable ambition, proper authority, passionate love... all these can so easily lead us astray when we take them for granted as commitments - and if these can, what may not? Tragedy shows us how our values become a self-comforting carapace, something in which to hide ourselves from ourselves, unless they are constantly being revitalised by a process of creative destruction. By the same token, it reveals on each tragic occasion not just the inadequacy of certain values as against others (which might then form the basis of compensation or mitigation), but the existential precariousness of our whole practice of evaluative living. That is why it leaves no values standing unquestioned, even when the destruction wrought out through a given tragic dilemma has been countered by superficially-apparent positives. ${ }^{6}$

Tragedy looming for ourselves, in other words - tragedy acknowledged as such and honestly anticipated - can be foreseen neither as mitigated nor unmitigated disaster, because we recognise that the experience of it is going to unsettle the very basis of that dichotomy. Oncoming climate and environmental disaster is only being taken seriously as tragedy when it is being foreseen as something which will transform our relevant values, across the board both those according to which the loss entailed will be disastrous and those by which we

\footnotetext{
${ }^{6}$ At the close of all great tragic drama, nothing remotely to be described as an unqualified positive is ever asserted. (The reader is invited to test this claim against his or her own reading.)
} 
might have been consoled or compensated for it - and will do so in ways which beforehand we simply can't know or condition for.

Anticipated real-life tragedy thus insists on itself as a peculiarly acute case of what has recently been described by the American philosopher Laurie Paul as 'transformative experience'. The defining feature of such experience is that it provides you with knowledge which you cannot acquire except by personally undergoing the experience in question, and which, so acquired, could be sufficient to "change your personal phenomenology in deep and far-reaching ways...perhaps by replacing your core preferences with very different ones" (Paul 2013: 8). Her original example, in the paper from which this comes, is the classically life-changing experience of giving birth to a child. The main interest of this for Paul herself, as a theorist of rational choice, is that if an experience is likely to have this effect, it cannot be evaluated beforehand for the purposes of weighing up whether or not to undergo it (nor, presumably, afterwards for the purposes of retrospective justification) because it may be expected to change the structure of values (prudential or moral) essential to one's prospective or retrospective evaluation - either to delete some and substitute others, or to change how one's different values are interpretively felt to stand to one another, so that in neither direction are we ever comparing by a common standard or from a single perspective. Characteristic further examples of such potentially transformative experience offered by Paul include gaining a new sensory ability (as with a cochlear implant for someone born deaf), undergoing major surgery, participating in a revolution and embracing a religious conversion.

Of course none of these (still less child-bearing) need be contemplated as a prospective tragedy. But to anticipate some genuinely tragic event which one knows one has to go through represents an acute case of the epistemological and existential jeopardy in which all these experiences place us, because here we know, just in virtue of the tragic framing within which what is coming presents itself to us, that our values are about to be wrenched and subverted across the board. And thus the prospect of climate tragedy threatens us with a profound form of loss, quite over and above the material loss and damage which it will entail - a loss of control at the deep level where our sense of ourselves as persons is generated.

We can bring out what is involved here by contrast with a definition of ideal-type control offered by Daniel Dennett in one of his perversely illuminating discussions of free will: "A controls $\mathrm{B}$ if and only if the relation between $\mathrm{A}$ and $\mathrm{B}$ is such that $\mathrm{A}$ can drive $\mathrm{B}$ into 
whichever of B's normal range of states A wants B to be in...for something to be a controller its states must include desires... about the states of something else" (Dennett 1984: 52 emphases in original). What is not said here, but is necessarily implied, is that A's desires must be independent of B's changes in state. The notion that A is in control of B, in other words, is the complex notion both that B varies only (on the relevant occasion) in response to A's desires, and also that A doesn't co-vary as a desiring agent across such variations in B. I control something if it does my will, but this requirement has to hold my will constant across whatever the thing which I am controlling relevantly does.

This being so, and facing inevitable tragedy for ourselves being to face radically transformative experience, it must therefore also be to face the prospect of an absolute or 'metaphysical' loss of control. It is not just that a painful process will contingently escape our ability to govern it, but that it will be one which dissolves the possibility of control as a matter of the logic of both tragedy and control. It will be, precisely, a process across which the values and desires by which the will shapes itself must be expected not to hold constant. Rather, what we must look forward to is the transformation into something as yet unknown of motives to which, as we look forward, we are still very powerfully attached. Prospective loss of control is thus prospective loss of values which ground our present identity. This is in a very real sense to foresee the prospect of losing our sense of ourselves.

But now, we have already seen reason to suppose that the implications of this recognition run far wider than tragedy, which only presents such loss of control at its most acute and threatening. For by just the same token, the various challenging but comparatively ordinary experiences which Paul discusses as potentially transformative must be seen as involving the same possible dissolution of control for the agent undergoing them. Just to the extent that I cannot make a rationally-weighed decision beforehand about whether to commit myself to such an experience, nor know in advance how I will evaluate it afterwards if I should do so, I have ceased to be in control of what is going to happen. And this prospect, once we are brought to acknowledge it, can be seen to confront us across a wide range of decisions generally unavoidable in any ordinary life - in relationships (do I follow through on this deep attraction?), in work (do I make this rather scary career move?) or in connection with one's health (do I take this reputedly mind-altering medication?), to name but several. In action we are always embarked in change rather than in Dennett's ideal agential control of what we are doing. 
VI.

As I indicated above, this paper is intended only as an exploratory foray. The topic deserves at least a book, which I at least hope to write. But for the purposes of provisional summary, I will now review briefly where I think the exploration has so far got us, and suggest some directions in which it might continue.

The tragedy of anthropogenic climate change, honestly recognised as a radically transformative experience through which humanity has now shortly to pass, must surely compel us to admit, in the first place, the general truth which it so drastically exemplifies: that humans are not in control of the most serious, life-significant events in which they are implicated. Coming to accept that this is the case is one vitally important way in which we will have to accustom ourselves to letting go.

Where might this recognition of non-control leave us as creatures who formulate and act upon values? The guiding thought here is that if we are to respond creatively to the way in which tragedy will put all our values to the question, we must learn to do something which might be described as letting go of our values, without giving up on them. That would mean, I suggest, learning to treat our evaluative commitments and principles as at best ongoing heuristics, subject to revision and reinterpretation in the light of experience, while at the same time accustoming ourselves to condition for and trust in the moral robustness of the unsearchable whole self which such principles always express (unsearchable, ungraspable in thought, because thinking about it necessarily objectifies what must be subjective to be what it is).

This is too large an issue to do more than gesture towards here. A phrase like "letting go of our values" might be expected to set alarm bells ringing: the opposite of letting go is holding on, and isn't holding on to one's values (through difficulties, in face of temptation...) the prime characteristic of moral strength? But one can hold onto values, as onto beliefs and relationships, as one holds onto Nurse - "for fear of finding something worse". There is a deeper moral resilience in trusting to what one's perhaps changing explicit values are expressing. One might live by a certain value, such as loyalty to a professed commitment or solemn promise, by striving always to control one's actions so that they were directed to goals which reflected the value. But mightn’t one instead (and perhaps more realistically, 
given the above considerations about 'control') simply embark oneself in action, to whatever provisional goal made best sense, entrusting oneself to the spirit of the value? The difference would be that between always deliberately setting out to do this kind of thing rather than that, and always trying to bring one's predispositions creatively to bear on where one's action (in its quality of always tending to slip away from one's intentions) was actually taking one.

Here we might note a worry about the whole idea of 'transformative experience': doesn't it in important kinds of case offer us a cheater's charter? After all, if my whole personal phenomenology and core preferences are liable to be altered by (say) plunging into this very tempting prospective affair, maybe my by-then-broken promise of faithfulness to my wife won't (then) look like such a big deal. But the point is that if I go ahead while tacitly banking on that self-gratifying outcome, I am actually refusing the real transformativity of the experience, while to embrace it will also be to accept that I might emerge having for the first time fully realised how precious to me my now-irretrievable faithfulness really was. Genuine creativity, in moral life as in art - as, indeed, anywhere - involves running radical risk. I honour values which have mattered to me no more by clutching them tightly to me than by slyly abandoning them: rather, I do so by taking their promptings with me into unpredictable life-change, where that is a decision of the whole being, in full awareness that this could renew me - or break me.

Letting go of one's values in this sense is not abandoning them. Abandonment is still (paradoxically) about control - I try to control my experience self-protectively by resiling from demands on myself which I have given up aspiring to meet. But creative letting-go is more like a standing-aside of the would-be controlling ego so that the value can find its own living way. What one is letting go of is, at bottom, a certain relation of the self to value - that, in fact, which was noted at the end of Section III as defining our currently-favoured view of rational agency. It is exemplified both by anxious attachment to and by self-defensive abandonment of one's values, since these are both relations of which 'self' and 'value' form distinct terms. In letting go, one is recovering the self as ongoingly constituted in the values which we find our actions expressing.

To repeat, there is no creativity without risk. A serious risk here is the evidently large scope for bad faith which goes with such a conception of value in action. Letting go of principled control so that the whole, dark self which one's values creatively express can realise itself 
open-endedly sounds bold and brave, but it could also very easily become one's preferred way of disguising from oneself special pleading, a habit of backsliding or even moral nihilism. Certainly, philosophical work needs to be done to explore the implications for moral integrity and active responsibility of this kind of evaluative letting-go. (For some initial orientation, one might look to the recent revival of interest in a broadly intuitionist moral particularism - see for instance Dancy 2004).

Some of the issues here may be sharpened by an example, and for this it will be best to return to the climate situation, since broad policy considerations for that future represent another main head under which this work needs to be advanced. These considerations are going to be very difficult, since they involve anticipating now, and conditioning for, how we might (as valuers to be transformed by the experience of climate tragedy) hope to make case-by-case practical sense of the broken world with which that tragedy will leave us (or some of us) to deal.

I take the idea of the 'broken world' from Tim Mulgan's fascinating and inventive book Ethics for a Broken World: he defines it as "a place where resources are insufficient to meet everyone's basic needs, where a chaotic climate makes life precarious and where each generation is worse off than the last" (2011: ix). Setting aside the intergenerational issues for the moment, consider that such a world will contain by definition what Mulgan calls 'survival bottlenecks' - situations in which there are more people making a claim on available resources than those resources will support in meeting their basic survival needs. Indeed, the whole world will be a gigantic bottleneck of this kind - with a still-growing global population increasingly straitened by reductions in the availability of habitable land, food production capacity, usable water and easily-deliverable energy, all complicated by the ramifying infrastructural derangement which increasing climate chaos will also entail.

In any such situation, humanity will be faced with the novel but appalling demand for institutional and regulatory procedures to determine not just 'who gets what' (the classic distributional problem in politics) but who survives. How are resource allocation decisions to be made, given that a direct upshot of such decisions will be that some people (on a global scale, perhaps many millions of people) will die and others won't? Unless they are going to be made simply by force majeure, with the accompanying breakdown of anything resembling civilisation, we must hope that these decisions will be made on some kind of principle which 
will allow law and governance to continue operating, and the obvious candidate for such a principle is that of justice. But what would justice entail in such a case?

Looking at this question from where we are now, it would seem to involve finding some way to take seriously the idea (which Mulgan canvasses) of a survival lottery. And surely idealtype justice for a survival bottleneck would mean (after perhaps excluding certain categories such as the very aged or the terminally ill who aren't going to make it anyway) something broadly equivalent to issuing everyone a lottery ticket, with only as many winning tickets as there are going to be packages of 'basic survival' resources available. Thereby everyone would have an equal chance, and the fairness of the procedure might go some way to encouraging acceptance (if only among those charged, dismally, with enforcement), since pure luck would determine who wins through - rather than the historical-geographical and climatic good luck (improved through centuries of exploitation and canny management) by which people from certain areas within the broken world will remain comparatively wellprovided with resources while others have been impoverished or indeed rendered destitute.

So much for the ideal. In actuality, of course, people finding themselves in anything approaching such straits will strive to protect their own families and communities, by institutional and legal means as far as possible and then in the last resort by force. And one possible, even tempting, response to this recognition is a kind of brutal realism: 'If justice requires me to put my kids into a survival lottery along with a lot of strangers, well, to hell with justice'. But for all the naturalness of that reaction, we will certainly need to hang onto some social organising principle with at least some of the characteristics of justice - some guiding rules for the allocation of responsibilities and benefits which have enough of equity, as well as of practicability, to be generally acceptable and thus workable - if all order, even in much more localised communities than we have recently been used to, is not to break down.

That being so, a response more in line with the considerations which we have been exploring - an attempt to let go of this crucial value without giving up on it - might be to say: given the radically transformative nature of the tragic process which will deliver us into the broken world, we simply can't know, pre-tragically, what the value of justice will mean for us posttragically, nor the pattern of relations with our other values (those of family and community loyalty in particular) in which it will then sit. While we can hardly help viewing such a world 
prospectively with horror - that, after all, is why the prospect of it is tragic - we perhaps need not view it, in its moral dimensions, with either cynicism or nihilism. We could instead trust to our moral creativity, making what arrangements for the future we practically can while remaining as generous and as open-hearted as we are able.

And then, of course, comes the real work: somehow, the possible forms of such preparation for the future will need sketching.

\section{VII.}

By way of concluding (or at any rate, of stopping for the moment) I return to Nietzsche.

If the foregoing is at all persuasive, we can now perhaps recognise Yeats' 'tragic joy' or the Nietzschean Dionysiac as our indefeasible delight, at this great crisis of the human adventure, in re-evaluative energy itself, energy released by radical challenge - our delight in that opening up of our self-understanding to creative destruction and renewal which tragedy, properly acknowledged, must bring. In this creative energy, the indestructible might of life, though trampled on by overweening human billions world-wide, now reasserts itself. Any hope which we can draw from the tragic prospect of what we must now endure, will then spring up as a renewed sense of that fundamental creativity: a sense that against whatever odds - even odds so great as massive climate change - life, in us as more widely, will go on re-making itself.

That sense affords us no guarantee. There is no certainty that life on Earth will not be ended by human actions. But we must let go of certainty, and of the desire for it. To do so is already to re-make life.

\section{References}

Andrews, N. 2017. "Transformation, adaptation and Universalism" Global Discourse 7:1. Beddington, J 2009. "World faces 'perfect storm' of problems by 2030, chief scientist to warn" The Guardian 18.3.2009 
https://www.theguardian.com/science/2009/mar/18/perfect-storm-john-beddingtonenergy-food-climate

Chen, E. 1989. The Tao Te Ching: a new translation with commentary. St Paul, Minnesota: Paragon House.

Dancy, J. 2004. Ethics without Principles. Oxford: Clarendon Press.

Dennett, D. 1984. Elbow Room: the varieties of free will worth wanting. Oxford : Clarendon Press.

Dyer, G. 2008. Climate Wars. Oxford: Oneworld.

Foster, J 2008. The Sustainability Mirage. London: Earthscan.

Foster, J. 2015. After Sustainability: Denial, Hope, Retrieval. Abingdon: Routledge.

Hulme, M. 2009. Why We Disagree about Climate Change. Cambridge: Cambridge University Press.

Lynas, M. 2007. Six Degrees: Our Future on a Hotter Planet. London: Fourth Estate.

Mulgan, T. 2011. Ethics for a Broken World. Durham: Acumen.

Nietzsche, F, 1872. The birth of tragedy ed. Geuss R. and R. Speirs 1999. Cambridge: Cambridge University Press.

Oreskes, N. 2004. "The scientific consensus on climate change" Science, 306(5702), 16861686.

Paul, L. 2013. “What you can't expect when you're expecting” Res Philosophica 92.2 1-23.

Read, R. 2017 "On preparing for the great gift of community that climate disasters can give us" Global Discourse 7:1.

Rockstrom, J., et al. 2009. "Planetary boundaries: exploring the safe operating space for humanity" Ecology and Society 14(2): 32.

Schopenhauer, A. 1819. The World as Will and Representation Volume I t rans. E. F. J. Payne, 1958. New York: Dover.

Schultz et al. 2005. "Values and their relationship to environmental concern and conservation behaviour" Journal of Cross-Cultural Psychology 36 (4) 457 - 475.

Schwartz, S. 1994. "Are There Universal Aspects in the Structure and Contents of Human Values?" Journal of Social Issues, 50 (4), 19-45.

Smith, P. and Howe, N. 2015. Climate Change as Social Drama. Cambridge: Cambridge University Press.

Yeats, W.B. 1967. Collected Poems London: Macmillan. 